\title{
TEORIA FEMINISTA E AÇÃO POLÍTICA: REPENSANDO A JUSTIÇA FEMINISTA NO BRASIL NA BUSCA PELA CONCRETIZAÇÃO DE DIREITOS
}

\author{
FEMINIST THEORY AND POLITICAL ACTION: RETHINKING \\ FEMINIST JUSTICE IN BRAZIL THE SEARCH FOR THE CONCEPT \\ OF RIGHTS
}

\author{
Joice Graciele Nielsson
}

\section{RESUMO}

Este artigo analisa os desdobramentos teórico/práticos do movimento feminista no Brasil, evidenciando que as desigualdades de gênero ainda são constantes, especialmente em momentos de fragilidade democrática. A partir de então, apresenta o Liberalismo Democrático-Igualitário como teoria de justiça feminista para o Brasil do século XXI. Tal proposta teórica está assentada nos fundamentos da multidimensionalidade, do igualitarismo, do cosmopolitismo e da democracia participativa, aliando elementos da teoria social participativa de Nancy Fraser, com o liberalismo igualitário das capacidades de Martha Nussbaum. Aliando à teoria das capacidades o potencial emancipatório e democrático da contrapublicidade fraseriana, busca constituir-se em um referencial político capaz de superar o déficit de empoderamento feminino na sociedade brasileira, superando as fragilidades dos feminismos do final do século XX, e recuperando o potencial crítico e emancipatório da filosofia feminista, tornando-a capaz de enfrentar o avanço do conservadorismo, do evangelicalismo político e do individualismo neoliberal.

Palavras-chave: Feminismo. Igualdade. Justiça.

\section{ABSTRACT}

This article analyzes the theoretical / practical developments of the feminist movement in Brazil, evidencing that gender inequalities are still constant, especially in moments of democratic fragility. From then on, she 
presents Democratic-Equal Liberalism as feminist justice theory for Brazil in the 21st century. Such a theoretical proposal is based on the foundations of multidimensionality, egalitarianism, cosmopolitanism and participatory democracy, combining elements of Nancy Fraser's participatory social theory with the equalitarian liberalism of Martha Nussbaum's capabilities. Combining with capacity theory the emancipatory and democratic potential of Fraserian counter-publicity, it seeks to constitute a political framework capable of overcoming the deficit of female empowerment in Brazilian society, overcoming the weaknesses of feminisms of the late twentieth century, and recovering the critical potential And emancipatory of feminist philosophy, making it capable of facing the advance of conservatism, political evangelicalism and neoliberal individualism.

Keywords: Feminism, equality, justice.

\section{INTRODUÇÃO}

Nas últimas décadas, o pensamento feminista tornou-se um componente crucial da filosofia e da teoria tanto política quanto jurídica. Partindo das primeiras reivindicações pela mera extensão de direitos, até seu amadurecimento a partir das pensadoras pós Simone de Beauvoir, a análise crítica por ele empreendida abriria, aduzem Biroli e Miguel (2012), um caminho de redefinição das próprias fronteiras do político, deslocando os debates centrais da teoria política e recolocando os termos em que é possível discutir, hoje, questões como democracia, representação, justiça, igualdade. Deste modo, a teoria feminista está promovendo uma verdadeira "refundação" de toda a filosofia e teoria políticas, ou mesmo "de toda a teoria social" (BIROLI; MIGUELI, 2012, p. 10).

No entanto, embora nos últimos anos tenha proliferado a diversificação de formas de vida cultural, sexual, de gênero, e o feminismo tenha se constituído no movimento social de maiores conquistas da história recente, a sujeição segue presente de múltiplas formas. 0 patriarcado e o capitalismo se rearticulam: a aparente liberdade das mulheres ocidentais se choca com novas formas de exploração no trabalho e no lar (principalmente de trabalhadoras negras, imigrantes ou refugiadas, que ocupam agora os postos feminilizados, pior 
qualificados e mais precários). Os discursos, tanto construtivistas quanto desconstrutivistas do gênero não têm sido acompanhados nem de avanços suficientes frente à desigualdade, nem de uma ruptura real do binômio sexual. A força de concepções da maternidade, o amor romântico heterossexual, de ideais de feminilidade impostos demonstram que o poder está fortemente enraizado em estruturas de longo alcance que se perpetuam, tornando a dominação heteronormativa uma constante.

Ocorre que, de alguma forma, descreve Fraser (2009a), o feminismo acabou perdendo muito de sua força emancipatória, em muito devido à própria complexidade interna do movimento, suas disputas e fragmentações, bem como a um desprendimento teórico diante da realidade concreta. Biroli e Miguel (2012) têm destacado, a respeito, que o corpus de reflexão teórica e pesquisa empírica feministas indicam uma filosofia política de enorme vigor, com variadas tradições e com um corpo de debates e de conceitos com crescente abrangência e sofisticação que, não raras vezes, beira o hermetismo. 0 risco deste processo, afirmam, seria permitir que tamanha complexidade descole o pensamento sobre o mundo das práticas sociais transformadoras que eles se propõem impulsionar, o que de certo modo, conforme a análise fraseriana, já vemse mostrando assustadoramente real.

Concretamente, o feminismo (re)surgente da segunda onda demonstrou uma trajetória impressionante, esforçando-se, afirma Fraser (2007) em transformar o imaginário político economicista prevalecente, e sustentando uma visão expandida da política que incluísse "o pessoal". No entanto, a partir dos anos 1980, "os insights anti-economicistas foram ressignificados e incorporados em um novo imaginário político que colocou questões culturais em primeiro plano. Capturado pelo imaginário culturalista, o feminismo reinventou-se como política de reconhecimento" (FRASER, 2007, p. 293), e foi atraído para a órbita da política de identidade, justamente no momento em que a democracia social ruía graças à pressão do neoliberalismo global, deixando-as sem defesa contra a selvageria das políticas de livre mercado nem ao chauvinismo de direita emergente. Resguardadas as especificidades locais e culturais, a "tendência das demandas pelo reconhecimento de eclipsar as demandas por distribuição foi geral, até mesmo mundial, apesar de o 
conteúdo dessas demandas diferirem" (2007, p. 298). O projeto feminista, em outros tempos um ambicioso projeto igualitário democrático de mundo, atualmente está formulado em termos individualistas que justificam formas de exploração ao invés de combatê-las.

Diante deste cenário, esta pesquisa reflete sobre a possibilidade de ressignificar o projeto feminista, a partir da construção de uma proposta multidimensional, igualitarista, cosmopolita e democrática de justiça com enfoque de gênero, denominada de Liberalismo Democrático-Igualitário.

Tal teoria parte da consideração de que a fragmentação das reivindicações por justiça feminista fez com que essas perdessem parte de sua capacidade emancipatória. 0 objetivo, portanto é rearticular conjuntamente as três dimensões essenciais da justiça de Fraser: a dimensão econômica da redistribuição, cultural do reconhecimento e política da representação. No cenário brasileiro, nenhuma das dimensões pode ser negligenciada: sobre a redistribuição, veja-se a persistente desigualdade social, intensificada pela feminização da pobreza. Quanto ao reconhecimento, veja-se práticas patriarcais como a conivência com o estupro e a violência, e desigualdades do mundo do trabalho. Sobre a representação, veja-se a sub-representação nos espaços de poder em nossa democracia.

Por tudo isso, uma teoria de justiça que se pretenda válida deve superar as visões compartimentadas o que impõe a tarefa de conciliar propostas teóricas aparentemente opostas. No caso em tela, serão abordadas a teoria social democrática de Nancy Fraser e a teoria liberal igualitária das capacidades, de Martha Nussbaum.

Fazer frente a todas essas injustiças requer, de acordo com Fraser (2013), o enfrentamento a três questões primordiais: o "o que”, “quem”, e o "como" da justiça, cuja gramática majoritária não tem mais conseguido fazer frente às peculiaridades de nosso tempo. Este enfrentamento será realizado na primeira parte do trabalho, momento em que o Liberalismo Democrático-Igualitário busca oferecer uma alternativa teórica a cada uma das três questões, mantendo como pressupostos essenciais: a multidimensionalidade; o igualitarismo; o cosmopolitismo; e a democracia participativa. Posteriormente, na segunda parte do trabalho, o artigo analisa de que modo a proposta por ele apresentada se 
constitui em uma perspectiva teórica capaz de fazer frente ao avanço do conservadorismo e à retirada de direitos em andamento no Brasil atual.

Diante deste cenário, o presente artigo reflete sobre a possibilidade de ressignificar o projeto feminista, a partir da construção de uma proposta multidimensional, igualitarista, cosmopolita e democrática de justiça com enfoque de gênero, denominada de Liberalismo DemocráticoIgualitário. Seu objetivo é rearticular conjuntamente as dimensões essenciais da justiça, as quais, no cenário brasileiro, não podem ser negligenciadas: a dimensão econômica da redistribuição; a dimensão cultural do reconhecimento; e a dimensão política da representação, aliando a teoria social democrática de Nancy Fraser à teoria liberal igualitária de Martha Nussbaum.

Para a consecução deste objetivo, o método investigatório utilizado é o fenomenológico, notadamente a partir das contribuições de Martin Heidegger e Hans-Georg Gadamer. Referida opção metodológica está assentada sobre a importância da linguagem, na medida em que não se busca um estudo a partir do qual o sujeito esteja "afastado" ou "cindido" do seu objeto. Pelo contrário, o objeto e o sujeito são constituídos pela palavra e por meio dela recebem a atribuição de sentido.

\section{O QUE, O QUEM E O COMO DA JUSTIÇA FEMINISTA}

Tempos atuais são tempos anormais, de uma crise social, econômica e política, que impõe dificuldades ao movimento feminista. Em tempos de justiça normal, aduz Fraser (2013), discussões sobre justiça assumem traços comuns a respeito do que seria uma reivindicação justa, os atores que podem fazê-las (indivíduos) e organismos aos quais dirigi-las (estados territoriais); sobre o âmbito da justiça e seus interlocutores (cidadãos de uma comunidade política); sobre o espaço que contempla reivindicações (econômico da distribuição); e quanto às clivagens que abrigam injustiças (classe e etnicidade). Já em tempos anormais a hegemonia do "que" distributivo é desafiada pela política de reconhecimento, de multiculturalistas a nacionalistas, e por militantes da representação; a supremacia do "quem" nacional-territorial é desafiada por localistas 
e comunitaristas, regionalistas, transnacionalistas e cosmopolitas; e o "como" é desafiado pelas expectativas democráticas de movimentos que questionam a prerrogativa de estados e elites determinarem a gramática da justiça. Que tipo de teoria de justiça serviria nessa situação? As pistas para uma resposta, ao menos parcial podem ser encontradas no reexame de tais nódulos de anormalidade.

\section{O “QUE” DA JUSTIÇA: CAPACIDADES MULTIDIMENSIONAIS}

As questões relativas ao "que" da justiça dizem respeito à sua substância. Quanta redistribuição é requerida, e de acordo com qual princípio e base informacional? As incertezas quanto ao "quê" refletem a problematização sofrida pela hegemonia distributiva de bens, predominante no pós-guerra, cuja ênfase em injustiças econômicas desconsiderou outras, como gênero, sexualidade, religião ou raça (FRASER, 2009b). Deste modo, "temos agora pelo menos três conceitos antagônicos do que representa o que da justiça: redistribuição, reconhecimento e representação" (FRASER, 2013:747), necessitando uma teoria tridimensional: a partir da luta de classes, a justiça contém uma dimensão econômica; para movimentos multiculturalistas, uma dimensão cultural; e para movimentos de democratização, uma dimensão política.

A construção de tal teoria não constitui um empreendimento fácil, pois polarizações entre distribuição e reconhecimento têm predominado na filosofia política. Quanto à teoria feminista, o renascimento da segunda onda, a dotou de uma força insurrecional capaz de questionar a dominação masculina nas sociedades capitalistas, moldando um movimento emancipatório que entrelaçava "em uma crítica ao capitalismo organizado pelo Estado, três dimensões distintas de injustiça de gênero: econômica, cultural e política" (FRASER, 2009a:14). Sua evolução, no entanto, tomou um caminho diverso, destacando a dimensão da política de reconhecimento. A primeira fase aproximou o gênero do imaginário igualitarista, e a segunda enfatizou a necessidade de "reconhecer a diferença", alterando a principal gramática das reivindicações no final do século. 
Tal virada, no entanto, coincidiu com o fortalecimento do neoliberalismo. "Encantada pela política de reconhecimento, a teoria feminista foi direcionada para canais culturalistas quando as circunstâncias requeriam redistribuição" (FRASER, 2007a:297), deslocando o imaginário igualitarista e subordinou lutas sociais às culturais, a política de redistribuição à de reconhecimento. Antes de chegar a um paradigma maior que incluísse ambos, "trocou-se um economicismo truncado por um culturalismo truncado" (idem), e ao descartar a relevância da igualdade, o feminismo se distanciou das desigualdades econômicas. Redistribuição e reconhecimento são debatidos como opostos: para proponentes da "diferença", estratégias de igualdade pressupõem o masculino como norma; para igualitaristas, abordagens da diferença fortalecem noções essencialistas de feminilidade.

Desse modo, configura-se a tese de Fraser (2009a): separadas umas das outras e da crítica social que as integrava, as esperanças da segunda onda foram postas a serviço de um projeto que estava em conflito com a visão holística mais ampla de uma sociedade justa, aderindo, inicialmente a um projeto político transformador, até que a fragmentação fez com que seu potencial emancipatório ruísse. Diante deste cenário, o Liberalismo Democrático-Igualitário, sustenta que o enfoque das capacidades, desenvolvido por Nussbaum, ofereça a base informacional capaz de responder ao "que" da justiça em tempos anormais. Este enfoque constitui um paradigma fecundo da justiça distributiva, no qual capacidades são espécies de molduras normativas que permitem a avaliação e o alcance do bem-estar, constituindo um espaço apropriado para que as três dimensões possam ser abordadas.

Nussbaum (2002) desenvolve uma espécie de liberalismo político igualitário neoaristotélico, estruturando instituições que garantam o desenvolvimento das capacidades individuais e ao mesmo tempo formem cidadãos democráticos, que se reconheçam como membros de um mundo interdependente, através do qual o cultivo de habilidades cognitivas, emocionais e comportamentais contribua para pensar os problemas em um cenário global complexo (NUSSBAUM, 2014a). Constitui-se um ideal democraticamente realizável, capaz de integrar a preocupação pela justiça sob o enfoque de gênero com a formação cosmopolita, e a capacidade 
como princípio avaliativo da liberdade efetiva que uma pessoa tem para realizar bem-estar. A igualdade a ser buscada por meio das capacidades respeita a diversidade e se preocupa com o potencial de cada um para acessar bens, recursos e direitos, transformando-os em bem estar, à luz das barreiras com as quais se deparam ao longo da vida.

Sua fundamentação kantiana considera que todos os seres humanos possuem um mesmo valor e dignidade, cuja fonte é seu poder moral, isto é, sua capacidade de viver a vida de acordo com a própria concepção de bem (NUSSBAUM, 1999). Este liberalismo político considera que: existem valores universais a serem resgatados na defesa da dignidade de todo ser humano em escala global; cada pessoa constitui um fim em si mesma; emoções morais devem ser cultivadas; há requisitos materiais para a realização da vida boa. A partir disso, a autora desenvolve sua lista de dez capacidades humanas ${ }^{1}$, como parte de uma determinação mínima da justiça, "uma sociedade que não as garanta para todos os seus cidadãos em algum nível mínimo apropriado não chega a ser uma sociedade plenamente justa, qualquer que seja seu nível de opulência" (NUSSBAUM, 2013a:91). Um conjunto mínimo de valores necessários à realização da justiça que deve ser garantido por toda sociedade que se diz justa.

Embora parta do procedimentalismo liberal, a introdução de elementos aristotélicos a faz superar críticas feministas ao liberalismo: seu excessivo individualismo; seu demasiado foco na razão; sua desconsideração do cuidado e o rol político da família. Diante da primeira, seu modelo de racionalidade prática aristotélica mostra que a primazia da liberdade não implica desconhecer os vínculos sociais, tendo como premissa ontológica entender o ser humano como finito e dependente. À segunda responde a partir do cultivo dos sentimentos morais e da imaginação narrativa como decisivos na consecução de uma vida boa. À terceira, desconsidera a posição de que só fazem parte do contrato membros plenamente cooperantes da sociedade, considerando que as "pessoas variam bastante em suas necessidades durante sua vida" (NUSSBAUM, 2013a:88). A teoria das capacidades desconsidera a visão contratualista de que a família é natural e o político é artificial, tomando todo ser humano como naturalmente político e dependente de justiça, pois a vida política não requer pré-requisitos, mas é sua condição natural. 
Trata-se, portanto, de uma teoria para a qual, ainda que as mulheres possam almejar vidas diferentes, todas são consideras portadoras de uma dignidade que lhes confere o direito moral a uma vida de escolhas não constrangidas.

Ao adotar o enfoque normativo das capacidades como resposta ao "que" da justiça com enfoque de gênero, o Liberalismo Democráticoigualitário pretende-se uma teoria multidimensional, considerando que a lista, como proposta por Nussbaum, abarca as três dimensões de injustiça previstas por Fraser: redistribuição, reconhecimento e representação, nos mais diversos itens da lista.

\section{O “QUEM” DA JUSTIÇA: DO INDIVIDUALISMO ÉTICO AO COSMOPOLITISMO}

Vencida a análise sobre o primeiro núcleo de anormalidade de uma teoria da justiça para tempos atuais, surge um segundo questionamento: igualdade de capacidades de quem? "A não ser que tenhamos uma forma adequada de entender o 'quem', a análise em relação ao 'que' não será útil” (FRASER, 2013:753).

Este debate reflete a ausência de uma visão comum sobre quem conta como sujeito da justiça e quais as necessidades que merecem consideração. Determinando quem conta como membro, a política delimita as outras dimensões, constituindo membros e não-membros e afastando os últimos do universo dos direitos. A injustiça emerge quando "as fronteiras da comunidade são desenhadas de tal forma a excluírem pessoas da chance de participarem em debates legitimados sobre justiça" (FRASER, 2009b:19), resultando injustas exclusões de indivíduos, a quem se nega a chance de formular reivindicações. Tradicionalmente as disputas assumiam o Estado moderno e seus cidadãos como unidade e sujeitos autorizados. Atualmente, afirma Fraser (2013:746), a hegemonia do "do quem westfaliano" é contestada por localistas, comunitaristas, regionalistas, transnacionalistas, cosmopolitas, identificando-se ao menos quatro visões diversas do "quem" da justiça: westfaliana, local comunitarista, transnacional-regional, e global-cosmopolita. 
Nos termos deste trabalho, a resposta se dá a partir do cosmopolitismo, tal como defendido por Nussbaum (2013a), considerando que a igualdade de capacidades deve ser garantida a todas as pessoas, em todos os lugares do mundo, independente do Estado, cultura, religião, gênero, sexualidade, classe, ou qualquer diferenciação. Nossa principal lealdade moral deve ser para com o ser comum da humanidade e os princípios devem respeitar o valor igual de todos os seus membros, considerando, segundo Nussbaum (2013c), dimensões capazes de construir sociedades em que o maior número possível de pessoas adotem e fomentem esta norma.

O cosmopolitismo é uma postura controvertida, à qual se opõe defensores de apegos a afiliações grupais ou nacionais (FRASER 2013). Para Nussbaum (2014b:10), no entanto "o nacionalismo e o particularismo etnocêntrico não são diferentes", e "apoiar sentimentos nacionalistas conduz até mesmo à subversão dos valores que podem conferir coesão à unidade nacional" (idem), substituindo valores de justiça por um ídolo colorido, como as bandeiras de um Estado-nação, que estabelecem uma perspectiva moral de que o "nós", seja patriótico, cultural ou de qualquer espécie, é o único relevante, demonizando um "eles" imaginário. Este tipo de pensamento "se converte em um chamamento geral em prol da supremacia local e da humilhação do outro" (NUSSBAUM, 2013b:12), que apenas a postura cosmopolita possibilitaria transcender. Esta não é uma tarefa fácil, pois embora acreditemos que todos os seres humanos têm o mesmo valor, nossas emoções são educadas a nos afligirmos apenas pelas pessoas que conhecemos, o que de fato, não é algo ruim. No entanto, devem-se encontrar mecanismos capazes de ampliar o alcance de tais sentimentos e da capacidade de imaginar a situação dos demais, até abarcar a vida humana em seu conjunto, incluindo todos os seres humanos em uma comunidade de diálogo e de interesses.

Tal estratégia preconizaria uma educação cosmopolita que propicie o reconhecimento da humanidade onde quer que ela se encontre, um aprendizado suficiente acerca da diferença para poder reconhecer objetivos e valores comuns, e um saber suficiente acerca desses objetivos para entender até que ponto eles são variados nas suas diferentes culturas e histórias. Tal educação cosmopolita e humanista, segundo Nussbaum (2014b), permitiria adquirir um maior autoconhecimento, permitiria o 
progresso conjunto a partir da construção de resposta às questões que implicam cooperação internacional, possibilitaria o reconhecimento de que o resto do mundo tem obrigações morais concretas, e se fundamentaria em diferenças que teríamos condições de defender.

Por fim, a postura cosmopolita de Nussbaum (2014b) supera a crítica à abstração, pois pressupõe, acima de tudo, valorar a diversidade das culturas e formas de vida, priorizando o justo sobre o bom, e estruturas de igual liberdade que protegerão a capacidade individual de escolher uma forma de vida. A liberdade de escolha torna-se a premissa básica de toda a ordem constitucional, pois "valorar a diversidade implica prestar um grande apoio a uma cultura pública compartilhada que anteponha o correto ao bom" (NUSSBAUM, 2013b:173). A questão fundamental tornase fomentar a diversidade sem hierarquizar, discriminar e oprimir, pois o compromisso com a liberdade pressupõe uma igualdade que limite a diversidade que razoavelmente possa ser promovida. Desse modo, defende-se a proposta teórica cosmopolita de que um nível mínimo de capacidades possa ser normativamente implementado em todos os países do mundo, a partir dos axiomas da igualdade moral humana e do individualismo ético, segundo os quais o valor último de preocupação moral são os indivíduos, e todas as pessoas são fins em si mesmas.

Embora a desigualdade de gênero seja um fenômeno mundialmente observado, tal proposta deverá ser viável e válida para abarcar todos os tipos de iniquidades sofridos pelas mulheres, nos mais diversos lugares e culturas do mundo, resguardadas as especificidades de sua manifestação concreta. É neste ensejo que Nussbaum se apoia em sua experiência na Índia $(2002,2012 a)$ para desenvolver sua proposta feminista cosmopolita, que incide sobre os arranjos e estruturas básicas nacionais e não apenas globais, mas que se apresenta válido para todas as esferas de relações entre pessoas morais no mundo. Tal proposta conduz à prescrição de uma espécie de "direito de saída" que deve ser acessível para as pessoas em todas as relações, de modo que comunidades e estruturas básicas funcionem como associações ou grupos de pertencimento (hipoteticamente) "voluntário", de modo que "direito de saída" seja estatalmente assegurado, e que nenhuma espécie de arbitrariedade ou 
diferenciação moral tornem o pertencimento a tais coletividades menos voluntário, inclusive para as mulheres.

A implementação desta proposta requer o enfrentamento aos principais argumentos contrários ao universalismo e ao individualismo liberal, resumidos por Nussbaum (2002): os argumentos da cultura, da diversidade e do paternalismo. Importa destacar que a proposta aqui delineada não exclui nenhuma opção de vida às mulheres, desde que oportunidades econômicas e políticas de saída estejam asseguradas, dado que espaços culturais como família e religião são historicamente construções de controle e dominação das mulheres, e defender direitos coletivos contribuiria para a perpetuação de tais coerções. A defesa normativa de que direitos individuais sejam subordinados a direitos culturais limita o espaço para a defesa da justiça de gênero, sendo incompatível com a defesa de gênero como questão de justiça.

Embora seja inegável a relevância da diversidade, muitas práticas culturais não são benéficas a todos, e seu questionamento não implica desconsiderar seu valor. O rol universal de capacidades não é incompatível com o respeito às escolhas individuais, pois seu objetivo é justamente proteger a liberdade, e, segundo Nussbaum (2002), a preocupação com a questão ética da diferença está presente na forma como a lista foi concebida ${ }^{2}$, respeitando como critério universal a oportunidade individual de escolha. Segundo a autora (2002:55), "devemos preferir um modelo normativo universal que permita às pessoas muita liberdade para buscar suas próprias concepções de valor, dentro de limites estabelecidos para a proteção da igualdade do valor da liberdade dos outros".

Por fim, a falta de empoderamento faz com que muitas mulheres pareçam satisfeitas com os costumes que respeitam. No entanto, se alguém que não tem educação formal nem "direito legal ao divórcio e possivelmente será agredida se procurar emprego, endossar tradições de modéstia, pureza e auto-abnegação, não é claro se deveríamos considerar esta a última palavra sobre o assunto" (NUSSBAUM, 2002:42). Como mostra Vita (2008:110), "teorias interpretativas se valem de uma noção de consentimento fraca para ter implicações legitimadoras", pois imersas em relações de poder. Seria, segundo Vita (2008:95) o "argumento das pequenas mercês": algo desejado nem sempre é valioso em termos de 
justiça, e algo não desejado não deixa de ser direito. Assim, "avaliar a vantagem individual de pessoas submetidas à desigualdades profundas somente por seus desejos e preferências significa corroborar a injustiça de que são vítimas" (VITA, 2008:5-6), pois a aparência de satisfação não pode determinar a efetiva realização, já que sem outras possibilidades as pessoas endossam a vida que levam, criando contextos de felicidade ilusória.

A perspectiva teórica deste trabalho questiona a defesa do relativismo cultural, pois, apesar de não condenar qualquer opção de vida das mulheres, defende que tais escolhas sejam válidas quando não implicam sacrifício de oportunidades, e feitas mediante um possível "direito de saída". Nestes termos, considera possível justificar posturas cosmopolitas que estabeleçam formas de igualdade de gênero universais a todas as pessoas do mundo.

\section{O “COMO” DA JUSTIÇA: A CONTRAPUBLICIDADE DEMOCRÁTICO-PARTICIPATIVA}

As preocupações com o como da justiça surgem com a inclusão da dimensão da representação política e a injustiça do mau enquadramento na teoria fraseriana, na esteira da globalização (BUNCHAFT, 2014), impondo uma necessária mudança paradigmática: justiça social passa a ser agora, justiça democrática.

A necessidade desta dimensão democratizante se manifesta em processos não-democráticos de estabelecimento da estrutura, monopolizada por Estados e elites transnacionais que, a um só tempo incluem e excluem, negando voz àqueles que podem ser prejudicados no processo. Estados e elites agem impedindo a criação de arenas democráticas onde as reivindicações dos últimos possam ser examinadas (FRASER, 2009b), excluindo a maioria das pessoas da participação nos discursos que determinam a divisão legitimada do espaço político, negando a chance de engajamento na tomada de decisões ${ }^{3}$. Isso revela um déficit democrático, explicitado na ausência de instituições onde disputas possam ser realizadas democraticamente; as lutas por justiça 
num mundo em globalização não serão bem-sucedidas desvinculadas das lutas por democracia.

As respostas tradicionalmente fornecidas se propunham a solucionar tal questão de forma monológica. No entanto, uma teoria para tempos anormais deve rejeitar tal premissa e tratar disputas de enquadramento de forma dialógica, como conflitos políticos cuja solução legítima requer uma discussão pública inclusiva (FRASER, 2013), requerendo instituições democráticas globais onde disputas possam ser colocadas e resolvidas (FRASER, 2013). Sob essa ótica, afirma Bunchaft (2014:153), a categoria esfera pública situada territorialmente sofre uma revisão crítica à luz de uma abordagem transnacional, do que resulta a "configuração de uma esfera pública transnacional na qual há uma rearticulação dos processos decisórios, superando as fronteiras dos estados nacionais territorialmente situados". As demandas por justiça não são discutidas apenas pelos públicos nacionais, e os reivindicantes não se restringem a discutir relações entre cidadãos.

A questão da esfera pública, portanto, adquire relevância, pois sua constituição e democratização são fundamentais. Ao analisar tal espaço, Fraser (1992) destacará que a exclusão das mulheres e de grupos estigmatizados foi um fenômeno central em sua constituição, e diversos tipos de desigualdades (privadas) penetraram na deliberação do espaço público, limitando o escopo dos problemas que poderiam ser contestados. Fraser, então, analisa a interpretação de Habermas (1962) sobre a esfera pública, considerada idealizada por não pressupor a exclusão estrutural de determinados grupos e não teorizar sobre as reivindicações contrahegemônicas que surgem a partir de públicos concorrentes.

0 ponto central da crítica não era apenas a idealização, mas a não percepção da existência de outros públicos concorrentes ao público burguês, como o contrapúblico feminista. Excluídas a priori da esfera pública hegemônica, que ignorava suas demandas e declarava seus interesses como privados, grupos de mulheres iniciam a formação do que a autora chama de "contrapúblicos subalternos", criando uma gama variada de publicações, comunicações e novos termos para descrever a realidade social. Contrapúblicos subalternos são arenas discursivas paralelas onde membros de grupos subordinados colocam em circulação 
contradiscursos para formular novas interpretações de suas identidades, interesses e necessidades (FRASER, 1992).

Em sociedades multiculturais, a ideia de igualdade política só faz sentido com a existência de uma pluralidade de arenas públicas em que grupos com diferentes identidades possam participar, mantendo um distanciamento estratégico dos públicos dominantes para tematizar reivindicações e demandas sobre identidades, interesses e necessidades com vistas à inclusão. Públicos concorrentes são parte crucial de um projeto emancipatório de esfera pública de reação à exclusão: uma vez que identidades, interesses e necessidades de determinadas mulheres são minimizados nos públicos dominantes, torna-se fundamental resgatar a ideia de esferas públicas contra-hegemônicas como estratégia de desconstrução de assimetrias e de inclusão social de mulheres.

Deste modo, "é por meio de contrapúblicos de resistência que os movimentos sociais ampliam a gama de conhecimento de injustiças publicamente articuladas, expandindo o universo da razão pública" (BUNCHAFT, 2014:88), inspirando a circulação de discursos de oposição aqueles excluídos da esfera pública oficial. Neste cenário, afirma Bunchaft, a própria existência de segmentos do movimento feminista que desconsideram mulheres transexuais como mulheres demonstra tais desigualdades, inspirando a circulação de discursos de oposição dessas minorias como estratégias de legitimação em debates públicos suscetíveis de desinstitucionalizar desigualdades de status que perpassam a esfera pública. Deste modo, a justiça global e a transformação da ordem mundial apenas se darão pela concretização da contrapublicidade em formas de auto-organização e autogoverno democráticas dentro da sociedade civil global e nacional.

\section{A CONTRAPUBLICIDADE DEMOCRÁTICA IGUALITÁRIA}

Esclarecidos os principais pontos relativos ao o que, ao quem e ao como da justiça, a questão da falta de empoderamento das mulheres diante das injustiças que sofrem permanece em aberto. Em outros termos, de acordo com Céli Pinto (2008): se é a justiça democrática que levará 
à implantação de capacidades como consequência da distribuição do reconhecimento e da representação, que cidadãos a definirão? Como poderá ser desmantelada a despolitização do debate sobre necessidades para que as próprias pessoas ou grupos subalternos consigam superar a deformação das preferências? A fragilidade das teorias vigentes, inclusive a própria teoria das capacidades evidencia-se na falta de reflexão sobre o empoderamento, afinal, os grupos injustiçados precisam perceber a si mesmos como vítimas de injustiças, se autorreconhecerem como iguais. Mas o autorrespeito não é um dado, precisa ser promovido.

Trata-se da politização do debate sobre necessidades, fazendo com que as próprias mulheres reconheçam a injustiça e a violação de dignidade a que estão submetidas, o que, de acordo com Fraser (1992), compreende três momentos: a luta para validar a necessidade como uma preocupação política legítima; a luta pela definição e interpretação das necessidades; e a sua implementação. A autora sublinha que as principais instituições responsáveis pela despolitização dos discursos sobre necessidades são a família, o mercado e o sistema político-administrativo. A família ao tratar certas questões como privadas, e a economia de mercado ao perpetuar relações de dominação baseadas na classe e no gênero.

A estratégia do Liberalismo Democrático-Igualitário para o empoderamento feminino na cultura política brasileira pretende expandir o potencial emancipatório das capacidades, agregando a esta a contrapublicidade, potencializando direitos universais das mulheres e o estabelecimento da lista de capacidades por públicos concorrentes, parte de um projeto emancipatório e participativo, capaz de se contrapor aos processos de exclusão. Para tanto, pressupõe que os agentes produzam dialogicamente entendimentos compartilhados sobre sua situação de mundo. Seu empoderamento e constituição como sujeitos autorreconhecidos são pré-requisito para a transformação estrutural, a ser conquistada mediante a contrapublicidade igualitarista, para quem é fundamental que as mulheres envolvidas e engajadas em redes solidárias de contrapúblicos subalternos moldem e interpretem um conjunto de necessidades e capacidades necessárias a suas respectivas condições de vida. Mesmo quando a interpretação das necessidades sofre os influxos 
da despolitização, o aporte democrático pode potencializar a reação contra-hegemônica, que se contraponha à dominação.

\section{O LIBERALISMO DEMOCRÁTICO-IGUALITÁRIO E A OFENSIVA CONSERVADORA E DE RETIRADA DE DIREITOS NO BRASIL}

Ao incorporar o elemento democrático participativo da contrapublicidade igualitária à teoria das capacidades básicas, o Liberalismo Democrático-igualitário configura-se uma teoria da justiça com enfoque de gênero para o Brasil, cujo momento histórico atual evidencia um grande paradoxo, uma vez que, mesmo com o avanço do movimento feminista e de uma série de medidas legais que visam à desinstitucionalização da desigualdade de gênero, toda sorte de problemas, como cultura do estupro, aqui abordada, a violência, o feminicídio, a sub-representação política, a desigual divisão do trabalho, dentre muitos outros, além de persistirem, têm-se acentuado.

Esta inquietação se agrava quando a realidade demonstra que, enquanto o feminismo avançava, debatendo essencialismos e performatividade, evidencia-se um retrocesso político e social promovido por forças conservadoras associadas a um patriarcado institucionalizado e a uma hegemonia dos padrões androcêntricos e heteronormativos. Feministas ficaram surpresas ao se dar conta de uma profunda aliança ocorrida entre fundamentalistas cristãos e conservadores em geral, que tomou conta do país, e ao perceberem que, ademais do crescimento da teoria e a prática feministas, o Brasil elegeu o congresso mais Conservador da história, colocando em marcha “o 'avanço' da 'vanguarda do atraso' composta, fundamentalmente, pela chamada bancada BBB: bíblia (pastores fundamentalistas), boi (agronegócio) e bala (ligada diretamente à polícia e às empresas de segurança, ao aparato repressivo e contra 0 estatuto do desarmamento). (FELIPPE, s.d., s.p.).

À luz das reflexões fraserianas, podemos dizer que, imersas no debate fragmentado das questões de gênero, e das disputas e exclusões internas, o feminismo perdeu grande parte de sua capacidade de intervir 
e transformar a realidade. 0 debate empreendido no campo cultural tem prevalecido, e deste modo camuflado questões distributivas que se acentuaram com a implantação perversa de desmonte dos direitos e proteções sociais conquistados a duras penas. Este processo está, em grande medida, centrado no mote da "defesa dos valores familiares" e da "sociedade brasileira dos homens de bem" (WERMUTH; NIELSSON, 2017). Neste contexto, setores conservadores e patriarcais brasileiros tem utilizado de forma bem-sucedida uma retórica antifeminista de reconhecimento para esconder a política de redistribuição e o desmantelamento dos direitos sociais. Temas como a proibição do debate sobre a suposta "ideologia de gênero" na escola, a tentativa de criminalização do aborto em caso de estupro, os debates em torno do Estatuto da Família (NIELSSON, 2019), estão na base da política de reconhecimento antifeminista, e antiprogressista (WERMUTH; NIELSSON, 2017).

No caso da cultura do estupro, esta situação se evidencia no momento em que a prioridade política passa a ser a proibição do aborto fruto de um estupro, e não o enfrentamento à própria prática do estupro. Através de diversos projetos de leis ${ }^{4}$ em curso, o objetivo se mostra culpabilizar, penalizar, dificultar ou ainda, impedir a prática de um direito estabelecido: o aborto de uma gravidez fruto de estupro. $\mathrm{Na}$ lógica patriarcal o estupro é culturalmente aceitável, e a mulher, um ser estuprável. Ao contrário do que coibir e punir a prática do estupro, os esforços se destinam a coibir o aborto, evidenciando uma nova ingerência sobre o corpo, a alma e a vida das mulheres (NIELSSON, 2019).

Todo este processo em curso demonstra algum sucesso da esfera conservadora e patriarcal em mostrar as feministas como profissionais de elite e humanistas seculares que desprezam as mulheres comuns, especialmente trabalhadoras e religiosas, desprezam a maternidade e a família. Até certo ponto essa visão do feminismo como elitista é equivocada, mas o fato é que o feminismo falhou ao tentar alcançar estratos das mulheres trabalhadoras e de classe baixa, atraídas na última década para a cristandade evangélica. Focadas apenas na política de reconhecimento, o movimento feminista falhou na tentativa de entender como a orientação religiosa delas responde às suas posições 
sociais, evidenciando-se um fenômeno que Fraser (2015) chama de "evangelicalismo político".

Este "evangelicalismo político" é uma "tecnologia do cuidado de si", especificamente adequada para cenários de avanço do capitalismo, o qual, segundo Fraser (2015), é um grande gerador de insegurança. Politicamente a "bancada evangélica" se alia às formas conservadoras, associadas ao patriarcado, promovendo a hegemonia de padrões androcêntricos e heteronormativos, bem como o desmonte das políticas sociais de seguridade e proteção, e deste modo, o próprio "evangelicalismo político" contribui para a construção de um cenário de inseguranças e incertezas. Por outro lado, mediante uma profunda retórica antiprogressista, atribui as incertezas ao avanço de valores "antifamiliares", como o aborto, oferecendo às pessoas um conjunto de práticas por meio das quais elas podem gerir a insegurança e a incerteza. Portanto, o poder de atração do evangelicalismo em relação às mulheres pobres, trabalhadoras e religiosas compensa o fato de que o feminismo tem sido frequentemente interpretado por tais segmentos como um movimento composto por mulheres brancas de elite, contrárias a valores que estas consideram importantes, como a maternidade e a família.

Evangelicalismo político e capitalismo neoliberal possuem uma íntima relação. Especialmente a partir do avanço da crise do capitalismo estrutural, em meados dos anos 1970, proliferaram iniciativas de reestruturação de formas de produção material da vida, que passaram a capturar a subjetividade mediante uma percepção da realidade marcada pelo atomismo do sujeito. A partir deste atomismo, a questão da diferença na conflituosidade acaba dissolvida na indiferença; a experiência no mundo da mercadoria e do consumo faz com que diferenças sejam diluídas em diversidades indiferentes. Neste cenário de extrema complexidade e incertezas, o saber religioso penetra profundamente nas massas e afeta o movimento feminista, bem como a outros movimentos críticos e de minorias, elevando significativamente os níveis de moralidade, de preconceito e de fundamentalismo.

Como superar tais desafios mobilizando politicamente as mulheres em uma sociedade como a brasileira da atualidade? 
Uma alternativa poderia ser a valorização da contrapublicidade igualitarista e seu potencial democrático capaz de superar tal realidade marcada pela fragmentação do indivíduo, que conduz uma diversidade desumanizada. A proliferação de contrapúblicos subalternos, que passam a tematizar, elaborar discursos e percepções sobre suas próprias necessidades e opressões, proporciona também a politização do debate sobre as condições individuais e coletivas da existência, seja na dimensão da reprodução, quanto do reconhecimento ou da representação. Podem ser capazes, portanto, de despertar um diálogo suficientemente democrático, capaz de fornecer um instrumental de superação da dimensão ideológica da vida pós-moderna neoliberal.

Contrapúblicos igualitários podem tornar-se espaços coletivos, em que indivíduos atomizados possam imergir em diálogos democráticoparticipativos, pautados pela escuta, pela troca de experiências, de vivências de discriminações, opressões ou sofrimentos, capazes de fortalecer os vínculos entre seus partícipes e a promover a construção de estratégias de luta conjunta, pautadas pelos respeito às diversidades e às diferenças. Desse modo, têm o potencial de se transformar em espaços capazes de restaurar a dimensão coletiva e política imprescindível a qualquer movimento crítico e contra-hegemônico, o qual, dialogicamente pode descontruir, além de assimetrias de poder, a ideologia individualista, consumista e atomizada produzida pelo neoliberalismo, pelo evangelicalismo político. No caso da cultura do estupro encontramos um exemplo de contrapublicidade igualitarista, na campanha "Eu não mereço ser estuprada" ${ }^{6}$, que mobilizou as redes sociais e a mídia brasileira, em resposta aos dados apresentados pela pesquisa do IPEA (2014) que evidenciavam a culpabilização da mulher em casos de estupro predominante em nossa sociedade. A campanha conquistou adeptos, multiplicando-se, especialmente na mídia digital, tornando-se um espaço de luta de questões de gênero, reunindo ativistas e usuários comuns de todo país. Neste, possibilitou-se o aprofundamento dos debates conceituais em relação ao tema, ultrapassando a mera campanha visual, e trazendo também relatos de vivência, mobilização para denúncia à violência contra mulher e diversas outras questões que tangenciam a luta de mulheres e feminista ${ }^{7}$. 
Debruçando-se sobre o contexto brasileiro de movimentos sociais nos últimos anos, é possível constatar um ambiente propício para a disseminação da contrapublicidade igualitária. 0 movimento feminista, em escala mundial, é um dos movimentos sociais que mais utiliza a lógica de produção simbólica e organização das redes sociais. As movimentações recentes, têm utilizado as redes sociais como plataforma para difusão de seus ideais e mobilização. Nesse sentido Alvarez (2014) situa o momento atual dos feminismos em termos de fluxos horizontais, verificando a multiplicação de campos, em especial os feminismos populares na cidade e no campo, que sinalizam uma popularização do feminismo. Alvarez (2014) conclui que o momento atual é de mobilizações, protestos e manifestações não institucionalizadas e mais fluidas, e de feminismos cada vez mais plurais e diferenciados entre si. Subalternos queer, por exemplo, reivindicam uma reação à heteronormatividade e à estrutura binária, permitindo às mulheres lésbicas e transexuais se engajarem em processos criativos estabelecidos em redes de solidariedade suscetíveis.

Estes desenvolvimentos atuais do feminismo brasileiro podem ser considerados como contrapúblicos subalternos, contribuintes da construção de esferas públicas contra-hegemônicas, capazes de problematizar a posição das mulheres nas relações de poder, e inspirar níveis elevados de empoderamento e um processo contínuo de atualização das capacidades. Somados aos demais aspectos de nossa teoria, que inclui sua multidimensionalidade e universalidade poderiam indicar um caminho em direção ao fortalecimento do feminismo e dos demais movimentos críticos.

A estratégia fundamental do Liberalismo Democrático-igualitário, para fazer frente a tal situação, consiste em não minimizar a temática das assimetrias e das lutas por poder na esfera pública, que se desvelam suscetíveis de definir quais relações de reconhecimento são legítimas e quais capacidades devem ser estabelecidas para um patamar mínimo de realização. Indubitavelmente, processos democráticos na esfera pública geral frequentemente mascaram a subordinação de grupos sociais desigualmente empoderados, que tendem a desenvolver estilos culturais desigualmente valorados, incapazes de alcançar a paridade participativa. Portanto, é uma teoria democraticamente estruturada, preocupada em 
contemplar as lutas contra as desigualdades de acesso ao poder na esfera pública e sintetiza um mecanismo necessário para alcançar um conjunto de capacidades em áreas principais do funcionamento humano.

\section{CONCLUSÃO}

Em meio aos debates internos afetos às teorias da justiça feministas desenvolvidas especialmente a partir de meados do século passado, o feminismo adentra o século XXI já consolidado como o maior movimento social e intelectual do século passado, mas convivendo ainda com toda sorte de opressões, discriminações e subordinações das mulheres, do feminino, e das manifestações diferenciadas de gênero. Isto porque a fragmentação e as disputas internas e o 'descolamento' da realidade concreta o fez, em muito, perder sua força crítica, seu potencial emancipatório e sua capacidade trasformativa, tornando imprescindível a recuperar seu potencial humanista e o rompimento de tais condições que, muitas vezes, o impede de reconhecer uma série de demandas, e o faz reproduzir hierarquizações e cesuras que combate. Do mesmo modo, precisa recuperar sua capacidade de diálogo com outros movimentos críticos, a fim de construir uma luta conjunta contra o avanço do poder patriarcal e conservador.

Diante deste cenário, foram desenvolvidos os contornos de uma teoria da justiça com enfoque de gênero, capaz de fazer frente às demandas conturbadas e complexas dos dias atuais, tidos como tempos anormais, especialmente no contexto brasileiro. Esta teoria, chamada de Liberalismo Democrático-igualitário, está assentada em quatro pressupostos fundamentais: multidimensionalidade, igualitarismo, cosmopolitismo e a participação democrática. Em sua formulação, responde os três principais nódulos de anormalidades das teorias atuais, conforme Fraser: o que, o quem e o como da justiça, constituindo-se em uma teoria que apregoa a defesa de uma lista de capacidades básicas a ser normativamente implementada em todos os países do mundo, mediante procedimentos democrático-participativos de contrapublicidade igualitária e de empoderamento das mulheres. Deste modo, o trabalho 
aliou a teoria democrática de Nancy Fraser à teoria das capacidades de Martha Nussbaum.

A estratégia fundamental do Liberalismo Democrático-igualitário consiste em não minimizar a temática das assimetrias e das lutas por poder na esfera pública, que se desvelam suscetíveis de definir quais relações de reconhecimento são legítimas e quais capacidades devem ser estabelecidas para um patamar mínimo de realização. Processos democráticos na esfera pública geral frequentemente mascaram a subordinação de grupos desigualmente empoderados, que tendem a desenvolver estilos culturais desigualmente valorados, incapazes de alcançar a paridade participativa. Portanto, é uma teoria democraticamente estruturada, preocupada em contemplar as lutas contra as desigualdades de acesso ao poder na esfera pública sintetizando um mecanismo necessário para alcançar um conjunto de capacidades.

É neste sentido que tal teoria oferece instrumentais teóricos práticos capazes de viabilizar o empoderamento das mulheres no Brasil. Inicialmente, porque apresenta uma base informacional multidimensional, que permite abarcar a multiplicidade dos problemas que atingem a vida das mulheres brasileiras, especialmente nas dimensões de reconhecimento, redistribuição, representação e sobrevivência, superando assim a visão fragmentada e, portanto, parcial e pouco revolucionária dos feminismos atuais.

Ao oferecer um conceito mais abrangente e inclusivo de pessoa, rompe com exclusões tradicionais advindas do contratualismo clássico permitindo incluir pessoas em situação de dependência e cuidados, bem como seus cuidadores sob o escopo da justiça. Supera ainda a dicotomia público-privada, que, do ponto de vista teórico deste trabalho, não tem razão de ser, uma vez que todos os espaços em que habitamos são políticos.

Pretendendo-se cosmopolita, busca superar as cesuras e divisões que têm hierarquizado as pessoas em nosso país, a partir de valores moralmente irrelevantes, dando importância a cada ser humano, independente das condições culturais, físicas, sociais, religiosas ou de gênero. Neste sentido, apresenta uma perspectiva humanista de consideração moral relevante inclusive para o movimento feminista, que muitas vezes têm replicado internamente cesuras e exclusões que deveria 
combater. Diante do questionamento: há, afinal, um sujeito do feminismo? Responde que sim, mas considera que, para além de mulheres, são sujeitos da justiça feminista todas as pessoas que vivem abaixo de um nível mínimo de capacidades em todas as dimensões aqui defendidas. Este é o verdadeiro potencial crítico e emancipatório do feminismo. Ao oferecer como princípio avaliativo a capacidade, ou seja, a possibilidade de colocar em prática, mas não o funcionamento em si, respeita a diversidade de escolhas éticas que as mulheres possam fazer em suas vidas, e as coloca na condição de agentes. Seu pressuposto fundamental é a liberdade. Outrossim, apregoa que as escolhas devem ser feitas em ambientes não constrangidos e com a garantia de um direito de saída.

Por fim, incorporando à teoria política feminista, a categoria da contrapublicidade igualitária, constrói estratégias democráticoparticipativas de desconstrução do patriarcado via empoderamento das mulheres nas esferas do reconhecimento, redistribuição, representação e sobrevivência, inspirando um processo constante de atualização das capacidades a serem garantidas. A relação entre contrapublicidade e o reconhecimento das especificidades interseccionais nas formas de subordinação é fundamental para se contrapor à lógica da cooptação promovida pelas forças neoliberais articuladas a "tecnologia do cuidado de si" do "evangelicalismo político". Em suma, a ideia da contrapublicidade igualitária pode visibilizar e tematizar as formas de opressão heteronormativas, classistas, racistas fora e dentro do movimento feminista, viabilizando alianças políticas contra-hegemônicas em esferas públicas paralelas transnacionais integradas por mulheres negras, lésbicas e transexuais.

Portanto, a proposta teórica aqui defendida visa garantir que todas as pessoas possam viver a vida que escolheram livremente viver, observadas as dimensões da redistribuição, reconhecimento, representação e sobrevivência, através da garantia de um nível mínimo de capacidades a serem normativamente implementadas em todos os lugares do mundo, e cuja viabilidade e atualização possam ser garantidas mediante a estratégia democrático-participativa da contrapublicidade igualitária. 


\section{NOTAS}

1 A lista disponível na obra Fronteiras da Justiça (2013a) contempla as seguintes capacidades: Vida; Saúde corporal; Integridade corporal; Sentimento, imaginação e pensamento; Emoções; Razão prática; Afiliação; Outras espécies; Diversão; Controle sobre o ambiente: (A) político e (B) material.

2 Por que a lista está sujeita a revisões, composta por itens genéricos, constituindo uma livre interpretação parcial da moral, não baseada em ideias metafisicas. Por que o objetivo a ser garantido é a capacidade, e não o funcionamento, atribuindo valor central às liberdades que garantam a existência do pluralismo, constituindo-se em base não autoritária para a legitimação de princípios políticos no mundo (NUSSBAUM, 2013a).

3 Talvez o exemplo mais atual deste processo descrito por Fraser seja o caso dos refugiados.

4 Destaca-se o PL 5069/2013, que torna crime o anúncio de métodos abortivos e a prestação de auxílio ao aborto, especialmente por parte de profissionais de saúde, de autoria do ex-presidente da Câmara, Eduardo Cunha (PMDB-RJ), que dificultando o acesso ao aborto já legalizado e regulamentado pela Lei 12.845/2013; o PL 1545/2011 que prevê pena de 6 a 20 anos para médico que realiza aborto, além da cassação do registro profissional; o PL 7443/2006 - apensado ao PL 4917/2001 -, que transforma o aborto em crime hediondo, e o PL 6033/13 - apensado ao PL 6022/2013 -, que revoga a Lei 12.845/2013. O PL 1413/2007 - apensado ao PL 313/2007 proíbe a distribuição, a recomendação pelo SUS e a comercialização pelas farmácias da pílula do dia seguinte; e o famigerado Estatuto do Nascituro (PL 478/2007), que proíbe o aborto mesmo em caso de estupro e transforma o aborto ilegal em crime hediondo, e ao qual estão apensados um projeto que prevê pena para quem realizar pesquisa com células-tronco (PL 489/2007) e outro que concede pensão à mãe que mantenha a criança nascida de gravidez decorrente de estupro (PL 3748/2008), popularmente conhecida como "bolsa-estupro".

5 A campanha teve início a partir de uma publicação no facebook realizada pela jornalista Nana Queiroz, fotografada sem a parte superior da roupa, cobrindo os seios com um braço e com o outro braço sobre a testa, escrito, em um deles "NÃO MEREÇO" e, no outro, "SER ESTUPRADA", acompanhada do seguinte texto: Uma pesquisa do IPEA mostrou, ontem, que 65,1\% dos brasileiros acha que mulher que mostra o corpo merece ser estuprada. Acreditam?! Você não concorda com isso? Nem eu! Então bora mostrar o corpo pra mostrar o quão revoltadas estamos? A ideia é que a gente tire a roupa e se fotografe, da cintura para cima, com um cartaz tampando os seios com os dizeres "Eu também não mereço ser estuprada" e postemos, todas juntas, ao mesmo tempo, online. Quem tá dentro?

6 A página se tornou um espaço compartilhamento de relatos de violência feitos por mulheres de vários lugares do país, motivando a interação entre os seguidores, e a expressão de sentimentos que demonstravam apoio e compaixão às vítimas, indignação aos atos de agressão e violadores, tristeza, admiração, alegria pela superação e afins. Propiciou-se a elaboração e a politização do debate sobre necessidades e injustiças, configurando uma rede de sororidade, de conselhos, mensagens de apoio e identificação, em um espaço de proliferação de um discurso contra-hegemônico ao predominante na esfera pública tradicional. Se constituiu, portanto, em uma arena discursiva paralela onde os membros dos grupos subordinados e injustiçados, nesse caso mulheres vítimas de violência pudessem inventar e colocar em circulação contradiscursos para formular interpretações oposicionistas de suas identidades, interesses e necessidades, bem como em lugar de acolhimento, recolhimento e reagrupamento, e espaço de construção teórica e prática para atividades dirigidas a públicos mais amplos. 


\section{REFERÊNCIAS}

ALVAREZ, Sonia E. Para além da sociedade civil: reflexões sobre o campo feminista. Cadernos Pagu, n. 43, p. 13-56, jan./jun. 2014.

BIROLI, Flávia; MIGUEL, Luis Felipe. Teoria política e feminismo: abordagens brasileiras. São Paulo: Belo Horizonte, 2012.

BUNCHAFT, Maria Eugenia. Esfera pública, reconhecimento e minorias: o diálogo Habermas-Fraser. Scientia Iuris, Londrina, v. 18, n. 1, p.153-180, jul. 2014.

FELIPPE, Igor. Um horizonte sombrio com o conservadorismo do congresso: redução da maioridade é o $1^{\mathrm{o}}$ ato. 2015. Disponível em: http://cartamaior.com. $\mathrm{br}$ /?/Editoria/Politica/Um-horizonte-sombrio-com-o-conservadorismo-doCongressoreducao-da-maioridade-e-o-1\%25BA-ato/4/33146. Acesso em: 6 jan. 2017.

FRASER, Nancy. Fortunas del feminismo. Traficantes de Sueños: Madrid, 2015. . Justiça anormal. Revista Faculdade Direito Universidade de São Paulo, v. 108, p. 739-768, jan./dez. 2013.

O feminismo, o capitalismo e a astúcia da história. Mediações, Londrina, v. 14, n. 2, p. 11-33, jul./dez. 2009a.

. Reenquadrando a justiça em um mundo globalizado. Lua Nova, São Paulo, v. 77 , p. $11-39,2009 b$.

Mapeando a imaginação feminista: da redistribuição ao reconhecimento e à representação. Estudos Feministas, Florianópolis, v. 15, n. 2, p. 240, maio/ ago. 2007.

Rethinking the Public Sphere: a Contribution to the Critique of Actually Existing Democracy. In: CALHOUN, Craig. Habermas and the public sphere. Cambridge: Mit Press, 1992.

HABERMAS, Jürgen. Strukturwandel der öffentlichkeit. Berlin/Neuwied: Luchterhand, 1962. 
INSTITUTO BRASILEIRO DE PESQUISA APLICADA. Tolerância social à violência contra as mulheres. Brasília: IPEA, 2014. Disponível em: http://www.ipea.gov. br/portal/images/stories/PDFs/SIPS/140327_sips_violencia_mulheres.pdf. Acesso em 3 jan. 2017.

KURUSAWA, Fuyuki. An alternative transnational public sphere? on anarchist cosmopolitanism in post-westphalian Times. In: FRASER, Nancy. Transnationalizing the public sphere. Massachusetts: Polity Press, 2014.

NIELSSON, Joice Graciele. Corpo Reprodutivo e Biopolítica: a hystera homo sacer. Revista Direito e Práxis, Ahead of print, Rio de Janeiro, 2019. Disponível em: file:///C:/Users/user/Downloads/40921-152667-2-PB.pdf. Acesso em: 01 dez. 2019.

NUSSBAUM, Martha. Paisajes del pensamento. La inteligência de las emociones. Barcelona: Paidos, 2014a.

. Educação e justiça social. Lisboa: Edições pedago, 2014b.

Fronteiras da justiça. Deficiência, nacionalidade e pertencimento à espécie. São Paulo: Martins Fontes, 2013a.

. Los limites del patriotismo: Identidad, pertenecia y ciudadanía mundial. Barcelona: Paidós, 2013b.

. India. Democracia y violencia religiosa. Barcelona: Paidós, 2012.

. Las mujeres y el desarrolho humano. Barcelona: Herder, 2002.

Sex \& social justice. Nueva York: Oxford University Press, 1999.

PINTO, Céli. Nota sobre a controvérsia Fraser-Honneth informada pelo cenário brasileiro. Lua Nova: Revista de Cultura e Política, São Paulo, n. 74, p. 35-58, 2008.

VITA, Álvaro de. 0 liberalismo igualitário. Sociedade democrática e justiça internacional. São Paulo: Martins Fontes, 2008. 
WERMUTH, Maiquel Ângelo Dezordi; NIELSSON, Joice Graciele. "Pela minha família, por Deus e pelo fim da corrupção": notas sobre o patrimonialismo na política brasileira contemporânea e a falência do Estado Democrático de Direito. Revista Direitos Fundamentais e Democracia, v. 22, n. 1, p. 46-79, jan./abr. 2017. Disponível em: <http://revistaeletronicardfd.unibrasil.com.br/index.php/rdfd/ article/view/870/498>. Acesso em: 25 jun. 2017.

Recebido em: 29-6-2017

Aprovado em: 19-12-2019

\section{Joice Graciele Nielsson}

Doutora em Direito Público pela Universidade do Vale do Rio dos Sinos/ UNISINOS-FURB; mestrado em Desenvolvimento pela Universidade Regional do Noroeste do Estado do Rio Grande do Sul; professora-pesquisadora do Programa de Pós-Graduação em Direito - Mestrado e Doutorado em Direitos Humanos - e do Curso de Graduação em Direito da Universidade Regional do Noroeste do Estado do Rio Grande do Sul; coordenadora da Pós-graduação Justiça Restaurativa e Mediação na mesma instituição; integrante do Grupo de Pesquisa Direitos Humanos e Biopolítica (CNPq). E-mail: joice.gn@gmail.com Universidade Regional do Noroeste do Estado do Rio Grande do Sul. Programa de Pós-Graduação em Direito

Rua do Comércio, 3000, Bairro Universitário. Ijuí - RS CEP: 98700-000 